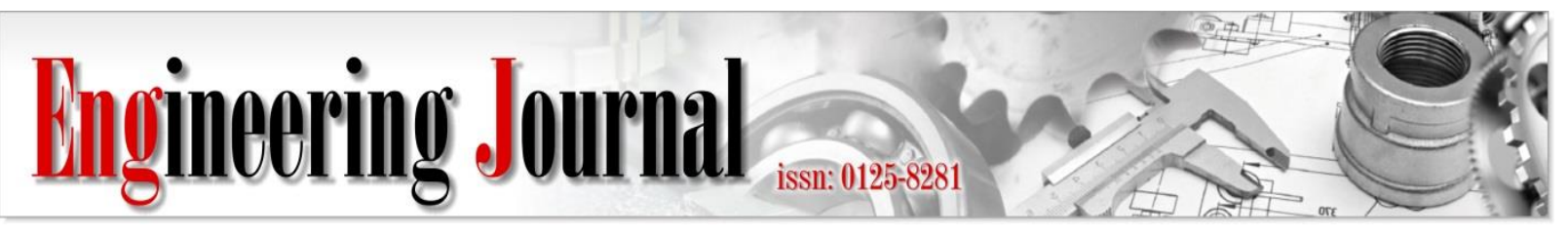

Article

\title{
Operational Models, Drivers' Compensation, and Bus Service Quality in Bangkok
}

\author{
Apiwat Ratanawaraha $^{1, a}$ and Saksith Chalermpong ${ }^{2, b, *}$ \\ 1 Department of Urban and Regional Planning, Faculty of Architecture, Chulalongkorn University, \\ Patumwan, Bangkok 10330, Thailand \\ 2 Transportation Institute and Department of Civil Engineering, Faculty of Engineering, Chulalongkorn \\ University, Patumwan, Bangkok 10330, Thailand

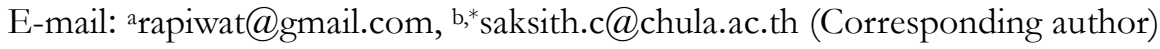

\begin{abstract}
This paper explores how operational models and compensation methods are associated with bus drivers' incentives and consequently bus service quality and safety in Bangkok. We crossanalyze data on bus drivers' compensation collected from a structured interview survey with data on passenger complaints and bus accidents compiled from governmental databases. Recognizing that the official statistics on bus accidents in Bangkok are undercounted, as the government includes only accidents with severe damages and injuries, we use passenger complaints as the proxy for safety levels. We find that private joint-service operators provide their drivers with far less compensation and benefits than the state-owned operator. The private operators also tie drivers' compensation and benefit levels to the numbers of working hours and trips, especially on routes where private operators can compete freely. These compensation methods incentivize drivers to work long hours beyond what is permitted by law, inducing fatigue and potential accidents. The key policy implication is that the bus policy aiming to improve service quality and safety should improve drivers' compensation and working conditions.
\end{abstract}

Keywords: Operational model, compensation, bus services, safety, service quality.

ENGINEERING JOURNAL Volume 25 Issue 3

Received 12 June 2020

Accepted 30 January 2021

Published 31 March 2021

Online at https://engj.org/

DOI:10.4186/ej.2021.25.3.85 


\section{Introduction}

Bus services in Bangkok have lost ridership substantially in the past two decades both in terms of number of passengers and mode share [1]. This downward trend is expected to continue due to several confounding reasons. Despite increasing travel demand thanks to urban population growth and suburbanization, state and private bus operators have not been able to expand coverage due to limited resources, low profit margins, and the government's fare-control policy [2]. By contrast, private vehicle ownership in Bangkok keeps rising, and the rail transit ridership continues to grow as the networks expand. These trends are expected to continue.

In addition to inadequate coverage and frequency, low service quality and safety concerns could also contribute to the decreasing bus ridership. Even though the official statistics on bus accidents in Bangkok's urban routes are low, i.e., only 27.7 per year between 2015 and 2017 compared with 301.33 per year over the same period in interurban routes, the numbers are likely undercounted. (See Table 1.) The government database includes only accidents with severe damages and injuries. News reports abound with stories about rude drivers and reckless driving that causes accidents. Some routes are particularly notorious to have more accidents and to receive passengers' complaints on low service quality [3, 4]. The problems seem particularly severe and frequent on routes with overlapping portions with other routes, as drivers tend to race for passengers.

Table 1. Official Accident Statistics of Public Buses in Thailand (Number of Accidents with Fatalities, Serious Injuries, or Significant Property Damages).

\begin{tabular}{lccc}
\hline Route Type & 2015 & 2016 & 2017 \\
\hline Urban routes (within Bangkok Metropolitan Region) & 26 & 24 & 33 \\
Interurban routes & 144 & 163 & 159 \\
Between Bangkok and Other Provinces & 93 & 127 & 82 \\
Between Other Provinces & 43 & 50 & 43 \\
Within Other Provinces & 306 & 364 & 317 \\
Interurban routes (Total) & & & \\
\hline Source: Official Statistics of the Department of Land Transport, Ministry of Transport (2019)
\end{tabular}

Such problems could be attributed to the ways in which the services are licensed and operated, and how and how much the drivers are paid. Although the state-run Bangkok Mass Transit Authority (BMTA) operate their buses on most major bus routes in Bangkok, private "joint-service" operators now cover more routes with more vehicles than the BMTA [5]. While the BMTA is the sole licensee to operate bus services, private operators are permitted to pick up passengers on routes where BMTA cannot cover. Some private operators have their own fleet and employ their own drivers. Others further subcontract individual operators to provide services on their behalf and share the farebox revenues [6]. Some private operators rent their vehicles to independent drivers on a daily basis, who shoulder fuel costs and sometimes maintenance costs and keep the fare revenue. While BMTA drivers are state employees who receive fixed minimum salaries and other benefits [7], drivers of private operators are paid differently [8]. A question arises as to whether operational models and compensation methods affect drivers' incentives and behaviors and consequently the quality and safety of bus services.

This paper attempts to explore the above question by cross-analyzing data on driver compensation collected from a field survey with the government's records on passenger complaints and accidents. The general hypothesis is that the operators of different operational models compensate their drivers differently, which affect the drivers' incentives and consequently service quality and safety in different degrees. After reviewing relevant literature in the following section, we provide an overview on how bus services are provided in Bangkok and on relevant laws that govern drivers' behaviors and working hours. The following section outlines the research methodology and data, followed by the findings. The last section concludes with policy implications and suggestions for future research.

\section{Literature Review}

Two related strands of literature serve as the conceptual basis for this study: one on how operational models affect bus service quality and safety, and the other on how compensation levels and methods affect drivers' behaviors.

One common debate on bus operational models is whether private operators can provide better and more efficient services than public ones. Previous studies find private operators perform better than public operators in France [9], Spain [10], and Britain [11]. But several other studies have provided empirical evidence refuting that claim [12-15]. It is important to note that these studies are based on experiences in cities in developed economies. Urban bus services in developing-country cities, such as Bangkok, are quite different in that they often involve a large number of informal operators, and that there are widespread institutional problems in monitoring and enforcing service quality and safety standards.

Service quality and safety issues of bus services in developing countries are often attributed to the hypercompetitive nature. Operators often use substandard vehicles, as they have limited resources to invest in new vehicles and equipment and have to keep the costs low. On-road competition to pick up passengers also induces dangerous driving behaviors. Drivers usually gain income based on distance and work hours, and mostly without labor protection and insurance. Informality and hypercompetitiveness are thus jointly the fundamental cause of low service quality and high safety risks of bus services in developing countries [16]. 
The debate on operational models is closely related to the arguments for and against bus liberalization. Empirical evidence shows mixed results on the effects of bus liberalization on service quality and safety in developing countries. Delhi's bus liberalization in the 1990s did increase the number of private buses, thus expanding the networks and increasing service frequency. But the service quality deteriorated in terms of reckless driving and the resulting accidents [17]. Similar problems occurred in Santiago de Chile after its bus liberalization in the 1990s. In this case, the operators had strong incentives to race on the road, because their revenue continued to be based on fare collection even after liberalization [18].

Several studies have identified the factors that affect customer satisfaction of bus service quality, including comfort and safety [19], in addition to accessibility and reliability [20,21]. Passenger satisfaction could be affected by the ways the services are licensed and operated. A recent study in Malaysia finds that the government has been lax in giving permits to individual bus operators, which leads to fierce competition among them. This results in low service quality, including overloading and delayed departure until the vehicles are full. However, the study finds that the lack of perceived safety on public buses is not attributed to the efficiency and discipline of the driver, but rather the lack of lighting infrastructure and congestion onboard [19].

A comprehensive review of the literature on commercial motor vehicles and safety finds convincing evidence that compensation levels and methods significantly influence driver behaviors [22]. Compensation generally acts as a pricing mechanism, but compensation's impact on drivers is complex. Several theories are used to explain the causal relationship between compensation levels and drivers' behaviors, including incentive theory, equalizing differences theory, efficiency wages theory, and fair wage theory.

Another set of theories focuses on compensation methods. Several studies argue that performance-based payment increases productivity [23], although the context of implementation is crucial [24]. But in the transport industries, such a compensation method could increase safety risks. For instance, truck drivers tend to work long hours when the compensation is low but increases with number of hours, thereby inducing more safety risks [25]. There remains scant literature that systematically explores the association between compensation methods and service quality and safety of urban bus services.

\section{Bus Operation in Bangkok}

In general, there are currently two operational models of bus services in Bangkok: the state-run BMTA services and the "joint services" run by private operators. In order to understand the current competition and operational models, we need to trace back to the original reasons why the BMTA was established as the sole licensee of city bus operation and what factors prevent the state agency from providing more efficient and demand-responsive services.
Up until the 1970s, public buses in Bangkok were operated by private operators. The services faced several problems, including bus shortage and inability to expand services, because of low profit margins and the government's fare control. In 1971, a West German transportation expert proposed that the bus operations be unified to reduce costs and improve service quality. Driven partly by a campaign pledge to provide free buses, the government hurriedly established the state-owned bus monopoly, the short-lived Mahanakhon Transport Company, which subsequently transformed into the BMTA [26]. The agency was granted operating licenses of all bus routes in Bangkok, and inherited the bus businesses from private operators, including their assets and employees [2]. It was in effect a clear policy shift from the laissez-faire model of competition and operation to the natural monopoly model.

Since its establishment, the state bus monopoly incurred huge debts from buying out previous bus managements. Having no resources to provide bus services due to slow transfer of businesses, the agency had to rely on the previous operators to do so. Despite the BMTA's subsequent purchase of new buses, the problem of bus shortage persisted due to deteriorating traffic congestion and rapid demand growth in the ever expanding city. As a result, a large number of unauthorized private operators used songtaews (converted pick up trucks) to provide bus services. In 1986, the government legalized these operators, while mandating them to change the vehicles to box-type minibuses for those operating on main streets [2]. The traditional songtaews continue to be allowed to run only in sois (secondary streets and alleys). The operating licenses of these routes were issued to the BMTA, which then subcontracted them to private operators.

The BMTA continued to accumulate operating deficit, and it was unable to respond to the burgeoning demand due to rapid suburbanization. With limited resources, the state agency could not expand services to cover all routes for which it was granted operating licenses. To circumvent the problem, beginning in 1986, the Department of Land Transport (DLT) invited private operators to operate under the BMTA's umbrella, and allowed the BMTA to issue joint-service contracts with private operators [2]. Since then, the number of jointservice operators has grown significantly; there are now more routes and vehicles operated by joint-service operators than the BMTA itself, as shown in Table 2. While the BMTA uses only full-size buses, the private operators use not only full-size buses, but also minibuses, converted pickup trucks, and passenger vans.

The service contracts between the BMTA and private operators cover general service-related issues, such as bus routes, frequency, and payment and fees. It does not stipulate drivers' working hours and conditions. Such issues are supposedly covered by the Transport Act, as revised in 1999 and in accordance with the 1998 Labor 
Table 2. Numbers of BMTA and Joint-Service Routes and Vehicles.

\begin{tabular}{lcc}
\hline Operator/Type of vehicles & No. of routes & No. of vehicles \\
\hline BMTA & 118 & 2,771 \\
$\quad$ Full-size buses & & \\
Private joint-service operators & 94 & 3,271 \\
Full-size buses & 42 & 895 \\
Minibuses & 98 & 2,059 \\
Songtaews (Converted pickup trucks) & 139 & 4,421 \\
Passenger vans & &
\end{tabular}

Protection Act. The law stipulates that a driver cannot operate a public transport vehicle consecutively longer than four hours without resting for at least half an hour, and that a driver cannot work longer than eight hours in one working day. The DLT as the regulator of the law mandates that all bus operators record their drivers' working hours in log books stored in the vehicles. Public transport operators have to ensure their drivers strictly follow safety regulations. Every driver has to follow public transport and traffic regulations, including being drug and alcohol free, no use of mobile phones while driving unless with headsets, and driving only on the left lane except when passing. If the drivers do not follow the rules and cause any accidents, the DLT could suspend or revoke the operators' licenses. But in reality the DLT just occasionally checks the log books and rarely conducts spot inspection, due to limited financial and human resources.

As for health and other benefits, only drivers officially employed full time by a legally registered operator with one or more employees are entitled to receive social security benefits. According to the 1999 Social Security Act, the coverage now includes not only sickness, maternity, invalidity, and death, but also child allowance, pension, and unemployment. The social security benefits do not extend to informal and temporary workers.

\section{Research Methodology}

Because no study has ever systematically examined the relationship between bus service quality and operational models and compensation methods in Bangkok, the primary aim of our research at this stage is to explore the problems in order to lay the groundwork for quantitative studies in the future. Even though we did not utilize rigorous statistical methods in this study, we collected both qualitative and quantitative data to test the following operational hypothesis: The root cause of poor service quality of Bangkok's bus services is the licensing/ operational model of subcontracting bus services to jointservice private operators, whose common compensation methods incentivize drivers to work long hours beyond what is permitted by law and to compete for passengers on the road. This in turn affects the service quality and potentially safety.
To examine this hypothesis, we selected bus routes with the largest number of complaints and conducted a structured interview survey of drivers, conductors, and dispatchers to obtain information about their operational practices and compensation methods on those routes. Then, we compared the compensation methods of the routes with the highest rates of complaints and reported accidents with those with the lowest rates. We categorized the routes into two groups: those run only by joint-service operators and those run only by the BMTA.

To represent the level of bus service quality, we obtained the data on passenger complaints from the 1584 Call Center, which is a DLT hotline that passengers can provide feedback on all bus services. The DLT hotline keeps a database that records complaint types, bus types, operator types, and route numbers. We were able to obtain a monthly report of the database that summarizes the bus routes with the five largest numbers of complaints from October 2016 to March 2017. The monthly data are compiled and sorted at the route level separately for those operated by the BMTA and those by joint-service operators. We then ranked the routes in order of number of complaints. As the number of complaints may depend on the fleet size on each route, we also normalize it by the number of buses for each route to better understand the relative frequency of complaints.

Originally, we also hypothesized that the compensation methods would also have noticeable effects on bus safety, as some routes are notorious for reckless driving and news reports abound with stories of bus crashes. We thus obtained data on accidents from the DLT's database of passenger bus accidents. But as it turned out, the number of accidents that occurred to BMTA and its joint-service buses in the study period was too small to conduct a systematic analysis of the eventual impact on bus safety. Only 24 bus accidents were reported and included in the official records in 2016. Official records of accidents include only severe crashes with serious injuries or fatality, most of which usually occur on intercity bus routes. Bus accidents in Bangkok frequently reported in the news tend to be of minor damages and are not included in the government's database. Therefore, we were not able to test the relationship between operational models and bus safety as measured by accident numbers recorded by the government.

Nevertheless, the records on passenger complaints, as shown in the following section, include categories that indicate safety concerns. One of the top complaints about the buses is "The bus was driven in a frightening manner." While we do not know how much such a driving manner leads to actual accidents, we can conjecture that the possibility is beyond ignorable levels.

To acquire data on drivers' compensation methods and levels, we conducted a structured interview survey at bus depots between 14 and 25 July 2018. Among the 94 full-size bus routes operated by joint-service operators, we randomly selected a total of 21 routes, including 18 routes with most complaints and three routes with no complaints. For each route, we conducted a structured interview of a 
dispatcher and three drivers, asking about the working conditions, compensations, and welfare benefits of drivers. We chose only those that operate full-size buses, so that we can compare directly with the BMTA operation, which only has full-size buses.

To compare between the models of private operators and public operators, we also collected information about the BMTA employee's compensation, fringe benefits, and work rules. We obtained the data from official BMTA documents, including the official salary structure and hiring announcements, and also from interviews with BMTA employees regarding their working conditions. We also conducted follow-up interviews with key informants who are bus enthusiasts for additional information about bus operation and compensation.

\section{Findings}

\subsection{Complaint Statistics}

As Table 3 shows, in general, the BMTA seems to provide better quality of service than the private operators, with slightly more than half of the total number of complaints on the private operators. The top three most common complaints for both types of operators are: buses not stopping at the designated stops, reckless driving, and rude behaviors of on-board staff. Curiously, the ranking orders are different. The top two complaints for the BMTA buses are that buses do not stop where they are supposed to, followed by dangerous driving, while the order is reversed for the private operators. Even though the statistics is not enough to test any hypothesis, we can conjecture that the BMTA is facing principal-agent problems. As their drivers receive guaranteed income and benefits, they do not necessarily have to pick up all passengers in all stops on the routes. By contrast, the drivers of private operators are incentivized to work longer hours and drive faster and recklessly, because their compensation is based on the working hours and trips and farebox revenues. This conjecture is supported by the empirical evidence presented in the following section.

Table 3. Most Common Complaints on Bangkok's Buses

\begin{tabular}{lc}
\hline Operator/Complaint & No. of complaints \\
\hline BMTA buses & 894 \\
The bus did not stop at a designated stop. & 778 \\
The bus was driven in a frightening manner. & 421 \\
The bus staff were rude. & 2,808 \\
$\quad$ Total number of complaints & \\
Joint-service buses $\quad$ Total number of complaints & 1,934 \\
The bus was driven in a frightening manner. & 557 \\
The bus did not stop at a designated stop & 5,249 \\
The bus staff were rude. & \\
& \\
&
\end{tabular}

By ranking all bus routes by the number of complaints, we find that bus routes operated by jointservice operators have much lower service quality than those operated by the BMTA. Table 4 shows that the numbers of complaints for routes operated by private operators are staggering, compared to those for the BMTA routes. Even after normalizing by the number of vehicles on each route, the numbers of complaints per vehicles operated by joint-service operators on the worst routes are still four to five times greater than those on the worst BMTA routes.

Table 4. Routes with the Largest Number of Complaints, October 2016 to March 2017.

\begin{tabular}{|c|c|c|c|c|c|}
\hline $\begin{array}{c}\text { Route } \\
\text { Number }\end{array}$ & $\begin{array}{c}\text { No. of } \\
\text { operators }\end{array}$ & $\begin{array}{c}\text { No. of } \\
\text { vehicles }\end{array}$ & $\begin{array}{c}\text { No. of } \\
\text { Complaints }\end{array}$ & $\begin{array}{c}\text { Complaints/ } \\
\text { vehicle }\end{array}$ & $\begin{array}{c}\text { Complaints/ } \\
\text { operator }\end{array}$ \\
\hline \multicolumn{6}{|c|}{ Joint-service routes } \\
\hline 8 & 3 & 66 & 153 & 2.32 & 51 \\
\hline 122 & 1 & 25 & 61 & 2.44 & 61 \\
\hline 108 & 2 & 37 & 59 & 1.59 & 29.5 \\
\hline 81 & 2 & 42 & 52 & 1.24 & 26 \\
\hline 39 & 2 & 46 & 50 & 1.09 & 25 \\
\hline 182 & 1 & 22 & 39 & 1.77 & 39 \\
\hline 57 & 1 & 42 & 21 & 0.50 & 21 \\
\hline 115 & 1 & 30 & 13 & 0.43 & 13 \\
\hline 133 & 1 & 37 & 7 & 0.19 & 7 \\
\hline 57 & 1 & 42 & 6 & 0.14 & 6 \\
\hline \multicolumn{6}{|c|}{ BMTA only routes } \\
\hline 25 & 1 & 40 & 18 & 0.45 & 18 \\
\hline 79 & 1 & 23 & 15 & 0.65 & 15 \\
\hline 65 & 1 & 22 & 13 & 0.59 & 13 \\
\hline 50 & 1 & 19 & 10 & 0.53 & 10 \\
\hline 515 & 1 & 36 & 10 & 0.28 & 10 \\
\hline 97 & 1 & 20 & 9 & 0.45 & 9 \\
\hline 15 & 1 & 21 & 7 & 0.33 & 7 \\
\hline 34 & 1 & 29 & 7 & 0.24 & 7 \\
\hline 84 & 1 & 52 & 6 & 0.12 & 6 \\
\hline 145 & 1 & 45 & 6 & 0.13 & 6 \\
\hline
\end{tabular}

October 2016 to March 2017

\subsection{Compensation Methods and Levels}

Based on the literature review, the survey results, and the additional follow-up interviews, we can categorize the compensation methods for private operators into two groups: basic compensation and additional incentives.

\subsubsection{Basic compensation}

Drivers of joint-service operators receive three types of basic compensation: daily allowance, farebox revenue sharing, and monthly salary. Although the majority of drivers are full-time employees of private operators, most of them are paid the daily allowance ranging between 215 and 325 baht (USD 6-10) in addition to receiving varying percentages of fare revenues. Generally, the daily allowance is not guaranteed, as the drivers must meet certain operational or fare revenue targets. For example, the drivers must drive at least four round trips, or the total 
fare revenue must exceed a certain threshold, such as 6,000 baht (USD 180) per day. So if the traffic congestion is very bad or somehow there are few passengers on board, the drivers would have to drive more until the thresholds are met in order to receive the daily allowance.

The fare revenue share is paid daily, although it is usually accumulated and paid on a weekly or monthly basis. Drivers normally make advance payment of fuel and other daily operating expenses, and keep proofs of payment for reimbursement at the end of each day. In practice, these expenses are paid from the farebox revenue. As Table 5 suggests, there are no uniform methods and levels of compensating the drivers. Because of the conditions imposed, these compensation methods are in effect performance-based.

Table 5. Summary of Regular Compensation of Employees of Joint-Service Operators.

\begin{tabular}{|c|c|c|c|}
\hline $\begin{array}{l}\text { Compensation } \\
\text { Types }\end{array}$ & Examples of rates & Conditions & $\begin{array}{c}\text { Used by routes } \\
\text { no. }\end{array}$ \\
\hline \multirow[t]{2}{*}{ Daily allowance } & 215 to 325 Baht & $\begin{array}{l}\text { Minimum of } 3 \text { to } 5 \\
\text { trips }\end{array}$ & $\begin{array}{l}8,43,57,81,84 \\
124,203, \mathrm{AC} 40\end{array}$ \\
\hline & & $\begin{array}{l}\text { Minimum fare box } \\
\text { revenue of } 3000 \\
\text { Baht to } 6000 \text { Baht } \\
\text { per day }\end{array}$ & $\begin{array}{l}6,8,84,115,122, \\
124, A C 11, A C \\
113\end{array}$ \\
\hline \multirow[t]{3}{*}{$\begin{array}{l}\text { Farebox } \\
\text { revenue share }\end{array}$} & $\begin{array}{l}12 \% \text { ( } 8 \% \text { for driver }+ \\
4 \% \text { for conductor) to } \\
17 \%(10 \% \text { for driver, } \\
7 \% \text { for conductor })\end{array}$ & & $\begin{array}{l}6,8,43,57,81,115, \\
122,124,127,183, \\
203,539, \text { AC } 113,\end{array}$ \\
\hline & $\begin{array}{l}1.4 \text { Baht per ticket for } \\
\text { driver }+1 \text { Baht per } \\
\text { ticket for driver }\end{array}$ & & $8, \mathrm{AC} 11$ \\
\hline & $\begin{array}{l}\text { Progressive share } \\
5000 / 5500: \\
14 \% / 16 \% \\
7500 / 8500 / 9000 / 100 \\
00: \\
8 \% / 10 \% / 12 \% / 14 \%\end{array}$ & & $115, \mathrm{AC} 40$ \\
\hline Monthly salary & $\begin{array}{l}5000 \text { Baht for driver } \\
3000 \text { Baht for } \\
\text { conductor }\end{array}$ & $\begin{array}{l}21 \text { working days per } \\
\text { month as assigned }\end{array}$ & 8 \\
\hline
\end{tabular}

\subsubsection{Additional working incentives}

In addition, joint-service operators use various forms of incentives to encourage drivers to increase fare revenues. These include incremental bonus allowances or incremental percentage of revenue for meeting revenue thresholds. For example, an operator of route number 203 pays a bonus of 50 baht per trip for the fifth and subsequent trips of the day. Other additional payment incentives are given for good attendance, early bird and long working day, late finisher, working on holidays, and annual bonus at year end or Chinese New Year, as summarized in Table 6.
Table 6. Additional Working Incentives by Joint-Service Bus Operators.

\begin{tabular}{|c|c|c|}
\hline Types of Incentives & Examples & Used by routes no. \\
\hline $\begin{array}{l}\text { Incremental bonus } \\
\text { based on farebox } \\
\text { revenue }\end{array}$ & See Table 7. & $6,8,43, \mathrm{AC} 40$ \\
\hline Good attendance & $\begin{array}{l}500 \text { Baht per month with } \\
25 \text { or more working day }\end{array}$ & 43 \\
\hline \multirow[t]{3}{*}{$\begin{array}{l}\text { Early bird \& long } \\
\text { working day }\end{array}$} & $\begin{array}{l}\text { First four trippers of the } \\
\text { day (start from around } 4 \\
\text { a.m.) get } 120 \text { Baht bonus } \\
\text { (to be split between } \\
\text { drivers \& conductors) }\end{array}$ & 43 \\
\hline & $\begin{array}{l}\text { First six trippers of the } \\
\text { day get } 50 \text { Baht bonus }\end{array}$ & 6 \\
\hline & $\begin{array}{l}\text { First trippers of the day } \\
\text { get } 40 \text { Baht bonus }\end{array}$ & $\mathrm{AC} 40$ \\
\hline Late finisher & $\begin{array}{l}\text { Last trippers get } 80 \mathrm{Baht} \\
\text { bonus. }\end{array}$ & 57 \\
\hline Working on holidays & Doubled daily allowance & 84 \\
\hline $\begin{array}{l}\text { Annual bonus \& } \\
\text { special occasions }\end{array}$ & $\begin{array}{l}\text { Year-end \& Chinese } \\
\text { New Year bonus }\end{array}$ & 84 \\
\hline
\end{tabular}

Table 7 shows examples of the payment schedules for incremental bonus that drivers could receive, depending on their farebox performance. The schedules vary across routes and operators. It is worth noting that this operator of Route 8 , one of the three operators on the route, has one of the most generous payment schedules for incremental bonuses, and the route also has the largest number of complaints.

Table 7. Examples of Incremental bonus based on farebox revenue.

\begin{tabular}{cccccccccc}
\hline $\begin{array}{c}\text { Routes } \\
\text { No. }\end{array}$ & \multicolumn{2}{c}{8} & \multicolumn{2}{c}{ AC40 } & \multicolumn{2}{c}{43} & \multicolumn{2}{c}{6} \\
\hline Threshold & $\begin{array}{c}\text { Fare } \\
\text { revenue } \\
\text { (per day) }\end{array}$ & Bonus & $\begin{array}{c}\text { Fare } \\
\text { revenue } \\
\text { (per day) }\end{array}$ & Bonus & $\begin{array}{c}\text { Fare } \\
\text { revenue } \\
\text { (per day) }\end{array}$ & Bonus & $\begin{array}{c}\text { Fare } \\
\text { revenue } \\
\text { (per day) }\end{array}$ & Bonus \\
\hline 1 & 5000 & 200 & 7500 & 100 & 4200 & 100 & 4000 & 150 \\
2 & 6000 & 200 & 8500 & 130 & 4500 & 200 & 5000 & 200 \\
3 & 7000 & 300 & 9000 & 150 & 5000 & 500 & 6000 & 250 \\
4 & 8000 & 700 & 10000 & 200 & - & - & 7500 & 300 \\
\hline
\end{tabular}

Note: The bonus is split by agreement between drivers and conductors.

Most drivers who are full time employees receive some minimum social security benefits, which entitle them to basic health care. Some employers also provide other fringe benefits, such as free or discounted accommodation. But we find that approximately $20 \%$ of them are not full-time employees, so they do not receive any social security benefits. 


\subsubsection{Working conditions: Sweatshops on wheels}

It is common for drivers employed by joint-service operators to start working before 5:00 a.m. and finish near midnight. The operational or fare revenue targets mean that drivers must work long hours to meet the income requirements. Due to the long working hours, it is a common practice for many drivers to work three consecutive days and take one day off.

While the majority of drivers are full time employees of bus operators, we find that approximately $20 \%$ of the drivers rent the buses from the private joint-service operators. Most of these drivers are regular renters, but pay the rent on a daily basis. The rental cost depends on whether maintenance costs are included. When renters pay for maintenance costs, the rent is lower, around 2,800 baht (USD 84) per day. But if the maintenance is included, the rent is higher, around 3,500 baht (USD 105) per day. Generally, renters pay for all day-to-day operating expenses, such as fuel around 1,000 baht (USD 30) per day, tolls, and keep all the fare revenue. The average net daily income after operating expenses is roughly 1,000 baht (USD 30) per bus, which is split between the driver and the conductor, who are often husband and wife, or family members. Aside from regular renters, some are part-time drivers, who rent buses only occasionally. Driver-renters do not receive any salary or welfare benefits, relying only on fare revenues. Nor do they have operational or revenue targets, and their working hours tend to be more flexible than those of employees.

\subsubsection{BMTA drivers' compensation and working conditions}

As shown in Table 8, we find that the compensation and working conditions of BMTA employees are much better than those of joint-service operators. They receive monthly salary, ranging from 10,150 to 37,500 baht (USD 305-1,124) for drivers and 9,040 to 22,500 baht (USD 271$675)$ for conductors, with an additional daily allowance of 50 baht for drivers and 20 baht for conductors [27]. They also receive the fare revenue share, albeit at a much lower rate than private operators' employees, at 0.10 baht per ticket for drivers and 0.05 baht per ticket for conductors.

Unlike joint-service operators, the BMTA strictly adheres to the eight-hour working-day rule, as stipulated by the labor law. Beyond the eight-hour limit, an overtime payment is made. The overtime rate, starting from 40 baht (USD 1.2) per hour, increases with the salary level, which in turn depends on the number of years of driving experience. Each BMTA employee receives one day off per week, and has a regular work schedule. They also have 10 paid-vacation days, 30-day sick leave, and 20-day leave of absence. BMTA employees also receive good welfare and fringe benefits. Health care benefits cover not only the employees themselves but also their immediate family, including parents, spouse, and up to three children. Educational expenses of employees' children are also covered. Finally, BMTA employees are entitled to free rides on all BMTA buses [28].

With relatively good compensation, it is unsurprising that significantly fewer complaints on reckless driving behaviors are made to BMTA buses than to joint-service operators. However, as shown in Table 3, a large number of passengers complained that BMTA drivers do not stop to pick up passengers at designated stops. Some passengers complained that BMTA drivers drive too slowly, especially near the end of their eight-hour shift, in order to earn extra overtime payment [7].

Table 8. Summary of Basic Compensation for BMTA Employees.

\begin{tabular}{llll}
\hline Compensation Type & \multicolumn{1}{c}{ Driver } & \multicolumn{1}{c}{ Conductor } & \multicolumn{1}{c}{ Note } \\
\hline Monthly salary & $\begin{array}{l}10,150-37,500 \\
\text { Baht }\end{array}$ & $9,040-22,500$ Baht & \\
Daily allowance & 50 Baht & 20 Baht & \\
$\begin{array}{l}\text { Farebox revenue } \\
\text { share }\end{array}$ & $\begin{array}{l}0.10 \text { Baht per } \\
\text { ticket }\end{array}$ & $\begin{array}{l}0.05 \text { Baht per } \\
\text { ticket }\end{array}$ & \\
Overtime & $\begin{array}{l}\text { Prorated by } \\
\text { monthly salary }\end{array}$ & $\begin{array}{l}\text { Prorated by } \\
\text { monthly salary }\end{array}$ & $\begin{array}{l}\text { For each hour } \\
\text { of work over } \\
\text { eight working- } \\
\text { hour day }\end{array}$ \\
& & For employees \\
Cost of living & 1,500 Baht & 1,500 Baht & $\begin{array}{l}\text { For } \\
\text { with salary } \\
\text { under 17,000 } \\
\text { allowance }\end{array}$ \\
& & & $\begin{array}{l}\text { Baht per } \\
\text { month. }\end{array}$ \\
\hline
\end{tabular}

Although the business models and compensation levels and methods vary among private operators, the proportions of income that their employees receive from fare revenue sharing are generally much larger than those of BMTA employees. Together with the evidence from the official statistics that private operators' drivers tend to drive more recklessly than those of BMTA drivers, we can conclude that employees' compensation methods clearly play an important role in influencing driving behaviors and service quality.

\section{Conclusions}

Our findings show that Bangkok's private bus operators provide their drivers with less compensation and benefits than the state operator, and their compensation methods incentivize the drivers to work longer hours than allowed by law. The data also show that the routes operated by private operators receive more passenger complaints than those operated by the state bus agency. We thus conclude that the operational models and their specific compensation methods are associated with the service quality of bus services in Bangkok. We conjecture that the joint-service model as practiced in Bangkok increases on-the-road competition and decreases the overall service quality, as private operators adopt 
compensation methods that incentivize their drivers to drive faster and work longer hours.

While the compensation methods based on fare revenue may account for the poor service performance of private operators compared to the BMTA, they cannot explain the performance variation among the private operators. A question thus arises as to what factors may account for the varying service qualities among private operators. Although we cannot directly answer this question with the findings from this study, we can offer some insights into the issue, using information that we gathered from additional field observation and informal interviews with several stakeholders.

An important factor that also induces racing for passengers is the number of overlapping services on the same routes. Routes with a large number of complaints, such as the notorious route no. 8 , usually run on the corridors with many overlapping routes, which tend to be high-density corridors with substantial bus demand. Being the last bus that follows a platoon of other buses on the same route could mean ending up with a near empty fare box. So such a scenario must be avoided at all costs. By contrast, in less dense corridors with few or no overlapping routes, drivers have little incentive to race for passengers, who are usually captive. Thus, fewer complaints about reckless driving are filed in these routes. Such a routing problem not only increases on-road competition and reduces service quality, but also directly affects the city's overall bus operation, as the overlapped routes increase the number of vehicles in the traffic while decreasing the number of operating cycles [29].

Ineffective regulation of joint-service operators stems partly from the current institutional arrangement. The DLT is the de jure regulator of all public bus operators, but with limited man power and technical resources. Since BMTA is a state-owned agency, it is supposed and expected to fully comply with the law, and the DLT loosely regulate bus operations by the BMTA and their joint-service operators. Therefore, the BMTA as the sole licensee of bus services in Bangkok serves as the de facto regulator of the private joint-service operators, not by legal authority, but by enforcing the subcontracts. However, the BMTA's resources are spread between its dual roles, i.e., as the bus operator itself and as the de facto regulator of private operators. The BMTA naturally focuses on the operator role and engages minimally in the regulatory role just enough to collect the joint-service fees. In addition, the government's tight control of fare does not reflect the true operating costs, so the private operators have to reduce costs by cutting corners. The DLT and the BMTA are thus hesitant to demand significant service improvement from the private operators, given the unrealistically low fare.

To enhance service quality and safety, regulators often place pressure on operators and drivers without addressing underlying causes. We believe that policy changes are direly needed that address drivers' compensation methods and levels, in addition to regulating and enforcing working hours and labor conditions. As far as we know, transport agencies rarely work with labor agencies. So intergovernmental cooperation between the two line agencies should also be encouraged so that compensation and working conditions of transport workers are improved. At the same time, the ongoing problems in fare regulation need to be addressed. Currently, the government can interfere with fare setting, as the regulatory board is filled with many members directly appointed by the Minister of Transport. Fearing a public backlash, the board rarely approves a fare hike. But with limited subsidies, both public and private operators cannot modernize their fleets, not to mention to improve their drivers' compensation levels and methods.

As of December 2020, the Thai Cabinet has approved a BMTA rehabilitation plan, which includes a proposal for the government to shoulder the BMTA's debt of more than 120 billion baht (USD 4 billion). Another key component of the plan is to hire private companies to procure and operate more than 2,000 electric airconditioned buses. The plan will also introduce a daily ticket priced at 30 baht for unlimited trips so as to help lower the commuting cost. It still remains to be seen whether these initiatives will be implemented and eventually lead to better overall service quality.

One key limitation of this research is the types and sizes of data sets used in the analysis. Future research could benefit from data collection methods that would allow for statistically rigorous analyses, including a questionnaire survey on rider perception and satisfaction. Future studies could also examine the grave financial conditions of the BMTA and most, if not all, private operators, as they greatly determine the current and future operational strategies and plans.

\section{Acknowledgement}

The authors acknowledge the two anonymous reviewers for their helpful comments and suggestions. We thank Chulalongkorn University's Faculty of Architecture for research funding, as well as Marut Chanroj and members of the Bangkok Bus Club for help with data collection.

\section{References}

[1] National Legislative Assembly of the Kingdom of Thailand. (2017). Study Report on Integrated Approaches to Solving Traffic Congestion in the Bangkok. Metropolitan Region. (in Thai) [Online]. Available: http://dl.parliament.go.th/handle/lirt/520894

[Accessed: 26 July 2018]

[2] I. Kakizaki, "Trams, buses, and rails," in The History of Urban Transport in Bangkok, 1886-2010, Chiang Mai, Thailand: Silkworm Books, 2014.

[3] Bangkok Post. (2015). Route 8 Bus Still the Worst [Online]. Available: www.bangkokpost.com/news/ general/757812 [Accessed: 26 July 2018]

[4] H. Kotani, "How Long Can Bangkok's Worst Bus Survive?," Nikkei Asian Review, 2015. [Online]. 
Available: asia. nikkei.com/NAR/Articles/How-longcan-Bangkok-s-worst-bus-survive [Accessed: 26 July 2018]

[5] Bangkok Mass Transit Authority. (2016). BMTA Annual Report 2559/2016 (in Thai) [Online]. Available: http://www.bmta.co.th/th/content/ [Accessed: 26 July 2018]

[6] A. Treerutkuarkul, "Call to revamp public buses contracting, few concessionaires run own services," Bangkok, Thailand: Bangkok Post, 2010.

[7] N. Wichitaksorn. "Why BMTA bus drivers don't pick up passengers?," (in Thai) Thailand Development Research Institute Research Brief, 2013.

[8] T. Fredrikson, "Behind the wheel of bus No. 8," Bangkok Post, 2014. [Online]. Available: www.bangkokpost.com/learning/advanced/407249 /behind-the-wheel- of-bus-no-8 [Accessed: 26 July 2018]

[9] K. Kerstens, "Technical efficiency measurement and explanation of French urban transit companies," Transport. Res. A-Pol., vol. 30, pp. 431- 452, 1996.

[10] G. De Rus and G. Nombela. "Privatisation of urban bus services in Spain," in J. Trans. Econ. Policy, vol. 31, pp. 115-129, 1997.

[11] J. Cowie and D. Asenova, "Organisation form, scale effects and efficiency in the British bus industry," Transportation, vol. 26, pp. 231-248, 1999.

[12] R. Fazioli, M. Filippini, and P. Prioni, "Coststructure and efficiency of local public transport: The case of Emilia Romagna bus companies," Int. J. Transp. Econ., vol. 20, pp. 305-24, 1993.

[13] P. A. Viton, "Technical efficiency in multi-mode bus transit: A production frontier analysis," in Transport. Res. B-Meth., vol. 31, pp. 23-39, 1997.

[14] J. Odeck and O. Sunde. (2001). The Relative Efficiency of Public and Private Bus Companies? [Online]. Available: https://core.ac.uk/download/pdf/41234492.pdf [Accessed: 26 July 2018]

[15] I. M. Garcia-Sanchez, "Technical and scale efficiency in Spanish urban transport: Estimating with data envelopment analysis," Adv. Oper. Res., 2009, Article ID 721279.

[16] R. Cervero, "Informal transport in the developing world," UN Habitat, Nairobi, 2000.

[17] K. Dhingra and S. Savant, "Implications of liberalisation of bus services: Case study of Delhi," CODATU VII, Cape Town, South Africa, 1998.
[18] A. Estache and A. Gómez-Lobo, "The limits to competition in urban bus services in developing countries," World Bank Policy Research Working Paper, No. 3207, Washington, D.C., 2004.

[19] H. M. Noor, N. Nasrudin, and J. Foo, "Determinants of customer satisfaction of service quality: City bus services in Kota Kinabalu, Malaysia," in Proc. Soc. Behav. Sci., 2014, vol. 153, pp. 595-605.

[20] H. Iseki and B. D. Taylor, "Not all transfers are created equal: Towards a framework relating transfer connectivity to travel behavior," Transport Rev., vol. 29, pp. 777-800, 2009.

[21] D. Abreha, "Analysing public transport performance using efficiency measures and spatial analysis: The case of Addis Ababa, Ethiopia," International Institute for Geo-Information Science and Earth Observation, Enschede, Netherlands, 2007.

[22] M. H. Belzer, "The economics of safety: How compensation affects commercial motor vehicle driver safety," Congressional Testimony, July, 2012.

[23] S. Fernie and D. Metcalf, "It's not what you pay; It's the way you pay it and that's what gets results: Jockey's pay and performance," International Industrial Relations Association Study Group 9, New Orleans, 1996.

[24] G. T. Milkovich and A. K. Wigdor, "Pay for performance: Evaluating performance appraisal and merit pay," N. R. C. Committee on Performance Appraisal for Merit Pay, National Academy of Sciences, Washington, D.C., 1991.

[25] M. H. Belzer, D. A. Rodriguez, and S. A. Sedo, "Paying for safety: An economic analysis of the effect of compensation on truck driver safety," Department of Transportation, Federal Motor Carrier Safety Administration, Washington, D.C., 2002.

[26] Bangkok Mass Transit Authority. (2016). BMTA History [Online]. Available: http://www.bmta.co.th/en/ content/bmta-history [Accessed: 26 July 2018]

[27] Bangkok Mass Transit Authority, "BMTA employee salary schedule," in BMTA Rules. Bangkok, Thailand 2015.

[28] Bangkok Mass Transit Authority, "Drivers recruit announcement," Bangkok, Thailand, 2016.

[29] I. Khemapech and L. Kidbunjong, "Analysis of excessive cost of overlapped bus route system in Bangkok," NIDA Case Res. J., vol. 7, no. 1, pp. 120149, 2015 . 


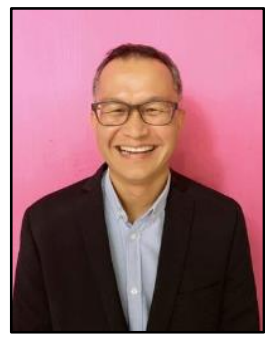

Apiwat Ratanawaraha is associate professor in the Department of Urban and Regional Planning, and an advisor at the Urban Design and Development Center, both at Chulalongkorn University in Bangkok, Thailand.

He is specialized in urban planning and development, infrastructure finance, technology and innovation policy, and futures studies. His ongoing and recent research includes projects on the futures of urban life in Thailand, the futures of clubs and commons, globalization of land, urban citizen science, and informal mobility in Thailand. He was a Visiting Assistant Professor at the MIT Department of Urban Studies and Planning, and a visiting scholar at the Harvard-Yenching Institute.

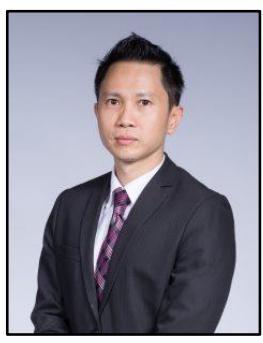

Saksith Chalermpong is associate professor in the Department of Civil Engineering at Chulalongkorn University, Bangkok, Thailand. He also serves as Deputy Director of Chulalongkorn University Transportation Institute.

His research interests include urban transport planning, public and informal transport, and equality issues in transport policy. He has published extensively in the field of transport and has provided consulting services for several government agencies in Thailand. Dr. Chalermpong received his bachelor's degree in civil engineering from Chulalongkorn University, his master's degree from M.I.T., and his doctoral degree from U.C. Irvine, both in the field of transportation. 